\title{
Occupational Safety with an Inclination towards Security and Health and Its Role in Retaining the Employees of the Regional Electrical Company of Sistan and Baluchistan
}

Fatemeh Khoshhal

Department of Management, Faculty of Humanities, Zahedan branch, Islamic Azad University, Zahedan, Iran

Mohammad Ghasemi

Assistant Professor, Department of Management, University of Sistan and Baluchestan, Zahedan, Iran Email: M_ghasemi@mgmt.usb.ac.ir

\author{
Doi:10.5901/mjss.2016.v7n3s3p288
}

\begin{abstract}
Nowadays the human force is the main spring of survival of organizations in the arena of competition and organizations by relying on the human resource cause the improvement of their activities in an increasing manner and have active involvements in various markets. The results indicate that even in case the recruiting operation to choose, appointment, training, and other employee-related activities being done in an efficient manner, without diverting sufficient attention to the issue of preserving the obtained results out of exercising management those deeds won't be so much outstanding. Thus, a special attention should be invested to the issue of retaining the manpower at the organization level. The purpose of present research is to scrutinize and consider the relationship between occupational stresses, safety attitude, organizational health, and job satisfaction in the job area and their role in retaining the employees of the Regional Electrical Company of Sistan and Baluchistan. The method of the research is descriptive-analytical. The statistical universe of the research involves the whole employees of the Regional Electrical Company of Sistan and Baluchistan which their number amounts to three hundred and fifty and at present are on duty and according to Morgan table the number of one hundred and eighty seven of the employees were chosen out of the statistical universe through random sampling method as the research sample. From among one hundred and eighty seven employees as the statistical universe of the research one hundred and fifty individuals participated in answering the whole questions of the questionnaire. The instrument which was used in this research was Graham Lowe's Healthy Organization Assessment (2010), Job Stress Questionnaire by Moghimi (2011), Safety attitudes Questionnaire by Zaidi (2011), the researcher-made job satisfaction and work environment Questionnaire in relation to research variables are being scrutinized. Validity of the questionnaire was achieved as 0.975 . The research data analysis was done at the descriptive and analytical levels. Research findings indicated that there is a direct and meaningful relationship between occupational stress and the safety attitude and the organizational health and job satisfaction and their role in retaining the employees of the organization and according to table of Friedman's test on retaining the company employees the utmost significance goes to the safety attitude and the least significance goes to occupational stress from among the research variables.
\end{abstract}

Keywords: occupational health and safety, job security, stress, stress management, maintenance staff.

\section{Introduction}

Nowadays retaining the merited employees is the main problem and responsibility of organizations. A problem which in case of getting resolved ends in multiple profitability and efficiency of organizations. Also, the augmentation of efficiency in organizations and their ever-increasing involves the development and efficiency of their employees and also sustaining their power of motive. (Vafayinejad et al., 2013)

Lack of security and health for the employees lead to the appearance of inefficient workforce which are not only a burden to a specific organization but also for the society. Nowadays the man power is accounted for as the main organizational resource and the success of the recent organizations is contingent upon the efficiency of their work force. It is up to us to empower ourselves to optimize the human resource and increase the efficiency of employees and meet their approval by reducing the accidents and elevating the level of hygiene and security and creating a healthy job area and contribute the organization in reaching its aims. 


\section{Statement of the Problem}

This research goes to scrutinize one of the main factors in retaining the employees that is security and the professional health. Occupational safety with an inclination towards security and health and its role in retaining the employees is a process that throughout it some deeds to provide the security and health of the employees of organizations are performed which includes the whole deeds which are carried out in relation to retaining and sustaining the body of employees such as creating hygiene and safety in the job area, performing the sports and health programs and also sustaining the spirit of interestedness of staff in the job and job area. Providing paying attention to and applying and observing these cases job security will be established in the employees and this leads to their job satisfaction which this thing in its turn has a considerable significance which leads to the elevation of performance of man power and leads to the augmentation of efficiency in the organization. (Wahabich, 2006)

For the time being security and health of the employees is accounted for as the part and parcel of the administrative system and is considered as one of the instruments of correct management since if the security and health and serenity and satisfaction do not create the management section of the organization can't direct the organization towards its aims. However, this issue should be done in due time and in a precise and incessant manner until a real conclusion is achieved. From among the organizations that from the onset of establishment (i.e.1981) have attached significance to the safety and health of employees is the joint stock Regional Electricity Company of Sistan and Baluchistan Province. In this research we go for considering that whether the occupational stress, safety attitude, organizational health, and job satisfaction are effective in retaining the organization employees? Providing a positive answer what kinds of deeds can be done towards the betterment of conditions? Safety and health of job area, optimizing the level of stress, and creating a proper occupational safety and finally creating job satisfaction are among the factors which should be taken into consideration for continuous improvement and elevation of organizations. Human resource constitutes the cornerstone of the real wealth of an organization. To reach this purpose it is necessary for the employees to enjoy a high level of satisfaction until they can produce value for the organization. Inexistence of occupational safety with an inclination towards security and health is one of the main threats which expose the organizational growth and development to an avalanche of obstacles.

\section{Theoretical Literature}

\subsection{Occupational stress}

Occupational stress can be considered as the accumulation of stress-inducing factors and the job-centered situations on which most of the individuals have consensus. Also occupational stress can be defined as the interaction between occupational situations and the idiosyncrasies of the employee in a way that the requirements of the job area is considered as more than the extent that the employee can actualize them.(Bavandpour, 2013)

\subsection{Job area safety}

Safety is defined as protecting the human and his/her efficiency against the harms and preventing the harms to human. In the industrial environments and in the presence of multiple machinery and tools workers are often exposed to several dangers. In alignment with the development of technology and augmentation of using machine in the process of production the probability of occurrence of dangers and accidents in such environments intensifies. The purpose of executing the security regulations and their relevant trainings is providing the possibility of a healthy area in a way that workers without any care and fear from industrial dangers go on with their jobs. (Kazemi, 2013). Safety and occupational health is not just observing the rights of others but the part and parcel of efficiency in any organization. (Wahabich, 2006)

\subsection{Organizational Health}

A healthy organization is a place in which the individuals come to their job eagerly and are proud of working in this place. In fact organizational health has a significant influence in the efficiency of the behavior of any system in terms of physical, psychic, security, dependence, meritocracy, and placing a high value on sagacity, professionalism, and the character of the beneficiaries and elevating their capabilities and doing their assigned responsibilities from their super systems. (Jahid, 2005) 


\subsection{Job satisfaction}

Job satisfaction consists in a limit of sensations and the positive attitudes of individuals towards each other. When a person states that s/he has a high job satisfaction it means that s/he really likes the job, loves it and has a good feeling on his/her job and places a high value on it. Job satisfaction is a positive or enjoyable sensational situation which is the aftereffect of job assessment or the experience of that person. This positive sensational situation contributes a lot to the physical and psychic health of individuals. From organizational point of view a high level of job satisfaction reflects the ideal organizational attitude which ends in attraction and retaining or survival of an employee. (Barahouyi et al., 2012)

\section{Review of Literature}

In the study to scrutinize the influential factors on the organizational survival of the employees in one of the major manufacturing companies which is under the aegis of The Mostazafan Foundation of Islamic Revolution the obtained results indicate that the internal environmental factors, external environmental factors, and job satisfaction has appropriated the first to third ranks in terms of its effectuality on the survival of individuals in the organizations. Also the relationship between the extent of job satisfaction and the influence of external environmental factors on the survival of employees is reverse; that is as much as the amount of job satisfaction in individuals decreases the influence of external environmental factors in the survival of the employee's increases. The concept of this relationship is that there may lots of individuals who are dissatisfied with their job but as a result of the stress from external factors stay in the organizations and this issue will by no means be proper for a decent company. (Ghazizadeh et al., 2006)

Scrutinization of the relationship between job satisfaction and the performance of employees in the casting industry indicates that there is a direct relationship between performance in the job area and the dissatisfaction with the job. The totally-satisfied employees have a little inclination towards submitting their complaint, have higher levels of somatic and mental health, and learn the responsibilities which are relevant to their job faster and/or confronting less job accidents. (Mardani et al., 2013)

In this research the relation between the job stress and function by considering the mediating role of job satisfaction was put into practice. The results indicated that: 1-Occupational stress has a negative and meaningful relationship with job satisfaction and functional performance and has a positive and meaningful relationship with turnover. 2-Job satisfaction has also a negative and meaningful relationship with leaving the public service but has a positive and meaningful relationship with functional performance. 3-Job satisfaction plays the role of a partial mediator in relation between occupational stress and functional performance. The evidence of this research indicates that for controlling the after effects of job stress on turnover and the functional performance it is necessary to concentrate on training the stress management and sustaining the job satisfaction in job areas. (Golparvar et al., 2013)

In another study the role of the relation between general health and the job satisfaction of the workers of a chipboard company was taken into consideration. Research findings indicate that there is a positive and meaningful correlation between general health and the job satisfaction of workers. Considering the relationship between general health and the job satisfaction of the workers the research puts emphasis on the necessity of providing safety and the standards of the job area, an elevation opportunity in due time, and proper and improving the conditions of job area. (Mehrabian et al., 2013)

In a study to investigate the security culture in one of the oil refineries based on Geller's model the results of the research indicated that in spite of the existence of a meaningful relationship between apprehensions and the performance of the employees the employees had a weaker view towards the observation of security standards. It seems that is necessary to work on this aspect until the security and the observation of security principles appear in the form of a value. (Taghdisi et al., 2013)

In a research titled as "The safety attitude in the rehabilitation clinics in the city of Ahvaz in the year 2013-14 the findings indicated that the total mean score for the safety attitude in the rehabilitation clinics of the city Ahvaz was evaluated to be higher than the average (i.e. more than \%50) Also, by considering that the awareness of the employees concerning the security issues had appropriated the lowest average among the aspects of security attitude the attention of the managers should be more concentrated on this aspect. (Elaheh Moghannibashi mansourieh, et al., 2013).

\section{Theoretical Framework of the Research}

Theoretical framework is a conceptual model and pattern based on the theoretical relations between a series of factors which are considered as significance in the area of research. To sum up, the theoretical framework speaks of the internal 
bonds between the variables which finally play roles in the dynamicity of the situation under study. (Sekaran, 2004) In this study to scrutinize the retention of the employees four aspects are taken into consideration in the Figure 1.

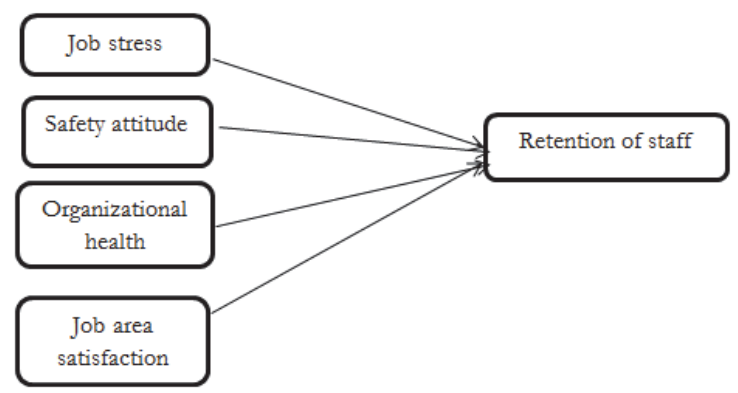

Figure 1: Theoretical framework of the research

\section{Research Hypothesis}

- There is a meaningful relationship between job stress and its role in retaining the employees of the company.

- There is a meaningful relationship between safety attitude and its role in retaining the employees of the company.

- There is a meaningful relationship between organizational health and its role in retaining the employees of the company.

- There is a meaningful relationship between Job area satisfaction and its role in retaining the employees of the company.

\section{Research Method}

In this research the descriptive-analytical method is being used. In this kind of research the researcher is in search of a tangible and real description of the features of the research subject. In this research in order to complete the literature review and background of the research the library research and the internet search has been used and in the section of field research a questionnaire is used. In order to analyze the collected data the descriptive-analytical statistics and the SPSS software have been used.

\section{Research Instruments and the How of Introducing it (Instrument of Data Collection)}

This research makes use of questionnaire method for finding and analyzing the research questions and in order to illustrate the current situation of the society by considering the findings of the author's survey questionnaire (i.e.The healthy organization assessment by Graham Lowe) (2010), Job stress Questionnaire by Moghimi (2011), Safety attitudes Questionnaire by Zaidi (2011) and the researcher-made work environment job satisfaction in relation to the research variables. In the whole steps of analyzing the research questions chi-square test with a significance level of \%95 has been carried out. All of the statistical analyses of this study have been done by means of SPSS software. The obtained data with an aid of statistical methods have turned into data and the research questions are put to the test and an attempt has been to extend the relations between variables and the statistics out of the sample by means of computer soft wares and determining the level of significance.

\section{Research Findings}

\subsection{Section one: descriptive findings}

In order to illustrate the general and total knowledge, the samples and describing the features of the statistical universe have been scrutinized. From among one hundred and eighty seven individuals from statistical universe of the research one hundred and fifty one individuals took part in answering the questionnaire that the data which is relevant to describing 
the features of this statistical universe have been inserted in the table's number 1 to 4 . This data illustrates the classification of sex, background of service, age, and the education level.

\subsubsection{Describing the features relevant to the sexuality of the sample}

Table 1: percentage distribution of respondents based on sexuality

\begin{tabular}{|l|c|c|}
\hline Sexuality & Frequency & Percentage \\
\hline Man & 130 & $\% 86 / 1$ \\
\hline Woman & 21 & $\% 13 / 9$ \\
\hline Total & 151 & $\% 100$ \\
\hline
\end{tabular}

\subsubsection{Describing the features relevant to the background of service of the respondents}

Table 2: percentage distribution of respondents based on the background of service

\begin{tabular}{|l|c|c|}
\hline Occupational record & Frequency & percentage \\
\hline To 5 year & 12 & $\% 8 / 3$ \\
\hline 5 to 10 & 11 & $\% 7 / 2$ \\
\hline More than 10 & 128 & $\% 84 / 5$ \\
\hline Total & 151 & $\% 100$ \\
\hline
\end{tabular}

\subsubsection{Describing the features relevant to the respondents}

Table 3: percentage distribution of respondents based on age.

\begin{tabular}{|l|c|c|}
\hline age & Frequency & percentage \\
\hline To 30year & 10 & $\% 6 / 6$ \\
\hline 30 to 40 & 26 & $\% 17 / 2$ \\
\hline More than 40 & 115 & $\% 76 / 2$ \\
\hline Total & 151 & $\% 100$ \\
\hline
\end{tabular}

9.1.4 Describing the features relevant to the educational degree of the respondents

Table.4: percentage distribution of respondents based on educational degree

\begin{tabular}{|l|c|c|}
\hline Educational degree & Frequency & percentage \\
\hline Up to Associate of Arts & 64 & $\% 42 / 3$ \\
\hline Bachelor of Arts & 63 & $\% 41 / 7$ \\
\hline Master of Arts & 24 & $\% 16$ \\
\hline Total & 151 & $\% 100$ \\
\hline
\end{tabular}

\subsection{Section two: Analytical findings}

In order to illustrate the current situation of society by considering the findings the survey questionnaires in relation to the research variables was scrutinized. In this section the research hypotheses by considering the questions which were inserted in the questionnaire which have been designed based on these hypotheses and the collected answers were analyzed. In this section in order to achieve the answers of the research questions descriptive and inferential statistics have been used.

\subsubsection{First Research Question (first hypothesis):}

Is there a meaningful relationship between job stress and its role in the retention of company staff? 
Table 5: Data analysis of the first research question

\begin{tabular}{|l|c|c|c|c|c|c|c|}
\hline Variable & $\mathrm{N}$ & $\mathrm{M}$ & $\mathrm{SD}$ & Test value & $\mathrm{T}$ & d.f & Sig. \\
\hline First hypothesis & 151 & 2.41 & 0.73 & 2 & 6.88 & 150 & 0.000 \\
\hline
\end{tabular}

Job stress

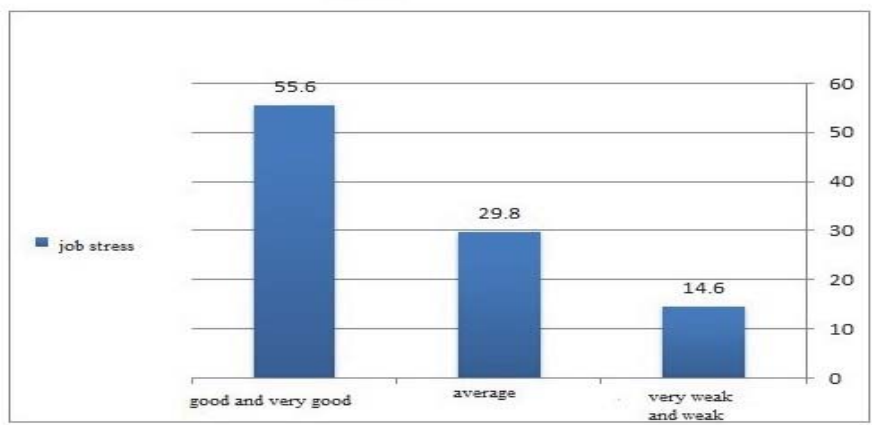

Diagram 5: Percentage distribution of respondents to the first research question

The obtained results out of table number five indicates that the mean and standard deviation of the respondents in relation to job stress and the role of retaining the company staff in the success of the project equals 2.41 , and 0.73 and since the calculated (t) (6.88) is more than the critical quantity of the table with a degree of freedom of 150 with a significance level of 95 . ( $p<\% 1)$, thus the observed difference with a hypothesized mean of $(0.000)$ is statistically meaningful. Thus, it can be concluded that there is a meaningful relationship between job stress and its role in retaining the company employees.

\subsubsection{Second Research Question (second hypothesis):}

Is there a meaningful relationship between safety attitude and its role in the retention of company staff?

Table 6: Data analysis of the second research question

\begin{tabular}{|l|c|c|c|c|c|c|c|}
\hline Variable & $\mathrm{N}$ & $\mathrm{M}$ & $\mathrm{SD}$ & Test value & $\mathrm{T}$ & d.f & Sig. \\
\hline second hypothesis & 151 & 2.55 & 0.63 & 2 & 10.69 & 150 & 0.000 \\
\hline
\end{tabular}

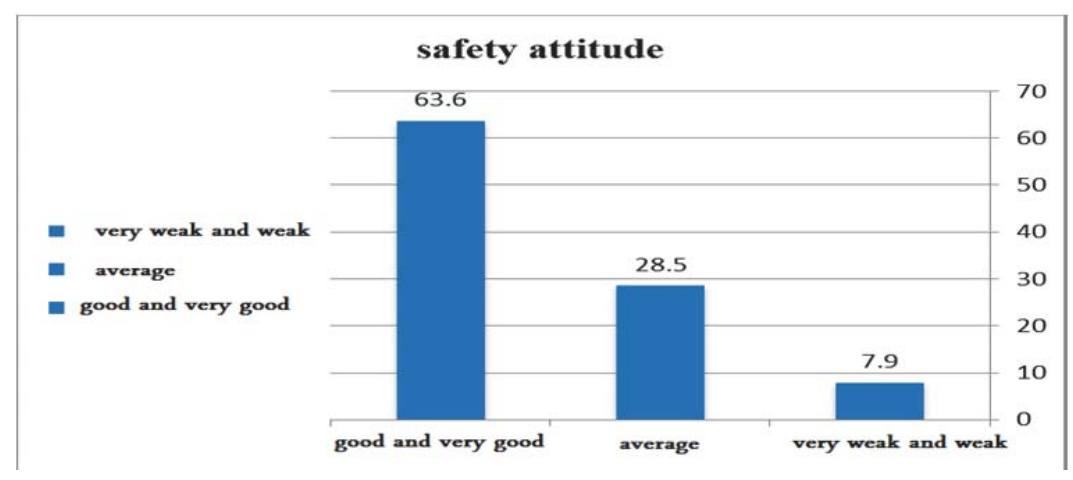

Diagram 6: Percentage distribution of respondents to the second research question 
The obtained results out of table number six indicates that the mean and standard deviation of the respondents in relation to safety attitude and the role of retaining the company staff in the success of the project equals 2.55 , and 0.63 and since the calculated (t) (1.69) is more than the critical quantity of the table with a degree of freedom of 150 with a significance level of 95 . ( $p<\% 1)$, thus the observed difference with a hypothesized mean of $(0.000)$ is statistically meaningful. Thus, it can be concluded that there is a meaningful relationship between safety attitude and its role in retaining the company employees.

\subsubsection{Third Research Question (third hypothesis):}

Is there a meaningful relationship between organizational health and its role in the retention of company staff?

Table7: Data analysis of the third research question

\begin{tabular}{|l|c|c|c|c|c|c|c|}
\hline Variable & $\mathrm{N}$ & $\mathrm{M}$ & $\mathrm{SD}$ & Test value & $\mathrm{T}$ & d.f & Sig. \\
\hline third hypothesis & 151 & 2.51 & 0.66 & 2 & 9.59 & 150 & 0.000 \\
\hline
\end{tabular}

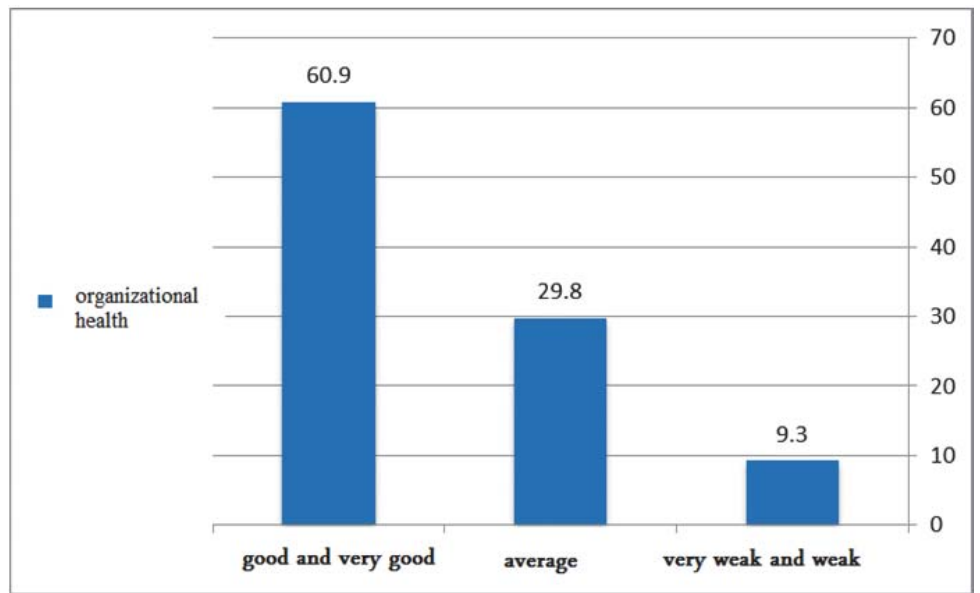

Diagram 7: Percentage distribution of respondents to the third research question

The obtained results out of table number seven indicates that the mean and standard deviation of the respondents in relation to organizational health and the role of retaining the company staff in the success of the project equals 2.51 , and 0.66 and since the calculated $(t)(9.59)$ is more than the critical quantity of the table with a degree of freedom of 150 with a significance level of 95 . ( $p<\% 1)$, thus the observed difference with a hypothesized mean of $(0.000)$ is statistically meaningful. Thus, it can be concluded that there is a meaningful relationship between organizational health and its role in retaining the company employees.

\subsubsection{Forth Research Question (forth hypothesis):}

Is there a meaningful relationship between Job area satisfaction and its role in the retention of company staff?

Table 8: Data analysis of the first research question

\begin{tabular}{|l|c|c|c|c|c|c|c|}
\hline Variable & $\mathrm{N}$ & $\mathrm{M}$ & $\mathrm{SD}$ & Test value & $\mathrm{T}$ & d.f & Sig. \\
\hline First hypothesis & 151 & 2.49 & 0.71 & 2 & 8.36 & 150 & 0.000 \\
\hline
\end{tabular}




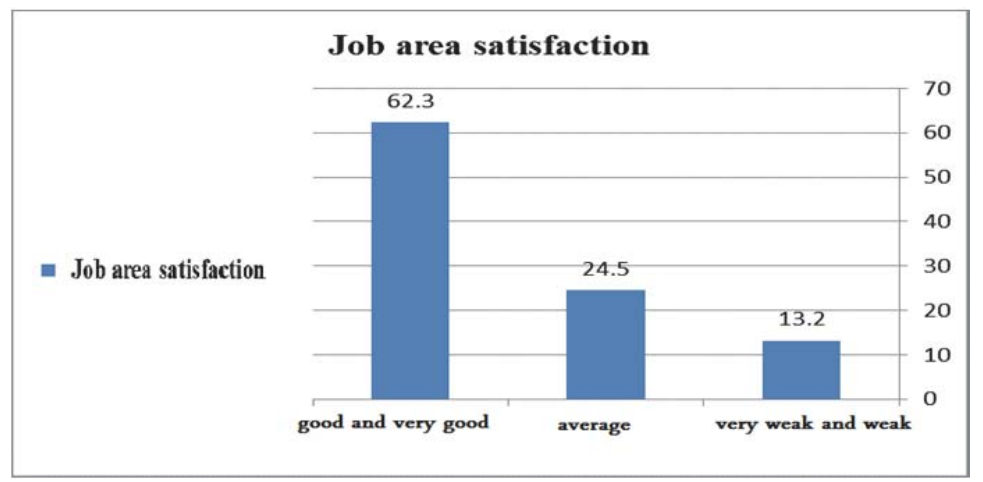

Diagram 8: Percentage distribution of respondents to the forth research question

The obtained results out of table number eight indicates that the mean and standard deviation of the respondents in relation to Job area satisfaction and the role of retaining the company staff in the success of the project equals 2.49 , and 0.71 and since the calculated (t) (8.36) is more than the critical quantity of the table with a degree of freedom of 150 with a significance level of 95 . ( $p<\% 1)$, thus the observed difference with a hypothesized mean of $(0.000)$ is statistically meaningful. Thus, it can be concluded that there is a meaningful relationship between Job area satisfaction and its role in retaining the company employees.

\subsubsection{Friedman Test}

Considering the quantity of the variables scoring (i.e. Job stress, safety attitude, organizational health and job satisfaction in the job area) and its role in retaining the employees or employees:

\section{Table 9:}

\begin{tabular}{|l|c|}
\hline Test Statistics & \\
\hline $\mathrm{N}$ & 151 \\
\hline Chi-Square & 36.140 \\
\hline Df & 3 \\
\hline Asymp. Sig. & .000 \\
\hline a. Friedman Test & \\
\hline
\end{tabular}

Consideration of the normality of the data: The above table indicates this point in terms of statistics that the variable sig $=0.000$ according to the criterion of decision at the $\% 5$ level of significance (i.e. $<0.05$ ) is normal.

Table 10:

\begin{tabular}{|l|c|}
\hline \multicolumn{2}{|l|}{ Friedman } \\
\hline Rank constant(RK) \\
\hline 2.33 & Job stress \\
\hline 2.63 & Safety attitude \\
\hline 2.55 & Organizational health \\
\hline 2.49 & Job area satisfaction \\
\hline
\end{tabular}

According to Friedman test the table indicates that the level of retaining the employees of the company earns the most significance and job stress earns the least significance from among the considered variables. 


\section{Conclusions and Recommendations}

The whole obtained results concerning the research hypotheses have been approved. According to the findings out of analysis there is a meaningful relationship between job stress and its role in retaining the employees of the company. The above-mentioned hypothesis was taken into consideration with twenty questions. The results indicate that $\% 55.6$ of the respondents held that there is a meaningful relationship between job stress and its role in retaining the employees of the company. \%29.8 of these respondents described this factor as average, and \%14.6 of respondents described it as weak and very weak and the result was that there is a meaningful positive correlation between job stress and its role in retaining the employees of the company. These findings are compatible with the findings by Golparvar et al. (2013), Afsari (2015), Azad marzabadi et al. (2007), and Bavandpour (2013). To explain these findings it can be said that we should seek for designing a system which leads to the reduction of job stress in the employees which is one of the influential factors in retaining the employees of the organization and an atmosphere which is teemed with fear and stress is improper. Stress-inducing factors can have a spoiling influence on the employees and reduces the amount of efficiency of employees although we cannot consider stress as a constant negative phenomenon and positive kinds of stress also exist (eustress) but anyhow stress has a widespread influence on the performance and activities of the members of the organization and learning the new ways to deal with this problem is very urgent.

In the other section of this research the relationship between security attitude and its role in retaining the employees of the company was scrutinized. This hypothesis was scrutinized by thirty seven questions. The findings indicate that only $\% 63.6$ of the respondents believed that there is a positive correlation between the safety attitude and its role in retaining the employees of the company. \%28.5 of the respondents considered this factor as average and \%7.9 of respondents were against these ideas and described it as weak and very weak which the result of this research approved of the relationship between safety attitude and its role in retaining the employees of the company. These findings are compatible with the findings by Taghdisi et al. (2013), and Mohammadfam et al. (2003) and Elaheh Moghannibashi et al. (2013) Thus, the criteria should be in a manner that a safe attitude or area arises. Elevation of safety in the job increases the rate of retaining in the organization. Among factors which are influential in retaining the employees safety of the job area is the most significant factor. Mangers and employers should get aware of the significance and value of retention. Correct designing of the job and the effectual supervision and education and familiarizing the employees with several aspects of safety from accidents.

Another result of the research was the existence of a meaningful relationship between organizational health and its role in retaining the organization employees. This hypothesis was taken into consideration by twenty five questions. The results indicated that $\% 60.9$ of respondents agreed on the efficiency of this hypothesis, $\% 29.8$ considered it a as an average or moderate factor and \%9.3 of the respondents considered it as a weak and very weak hypothesis. Thus, this conclusion will be achieved that there is a positive and meaningful relationship between organizational health and its role in retaining the employees of the company. In the healthy organizations employees are committed and conscientious, have a high spirit and performance and cause the establishment of an area which individuals like to bring with themselves to their job area and are proud in working in their job area. These findings indicate that the results of these studies are compatible with the results of studies by Nasiripour et al. (2012) and Hagigatjou and Nazem (2008), and Mehrabian et al. (2013).

In another section of this research the relationship between job satisfaction at job area and its role in retaining the employees of a company was scrutinized. The obtained results approved of the positive and meaningful relationship between job satisfaction at job area and its role in retaining the employees of the employees. To approve and reject the above hypothesis twenty questions were posed and the result indicates that $\% 62.3$ of the respondents described this factor as weak and very weak. Thus, there is a meaningful relationship between job satisfaction in job area and its role in retaining the employees of the company. The key and effective element in any organization is its man power among whom there are interrelationships and an attempt should be made for achieving the satisfaction of the employees and preventing them from leaving their service. Job satisfaction of employees has a considerable influence in elevating their spirit and the output of their work. These findings are compatible with the results of the researches by Ghazizadeh et al. (2006), and Jahangiri et al. (2008), and Afjeh et al. (2013), and Vafayinejad et al. (2013).

\section{References}

A report on the Universal journalism. (2011).

Afjeh, Seyyed aliakbar. Saleh ghaffari, Adel. (2013). "Factors influencing the retaining and the job abandonment of the knowledge-based employees. Website of Management essays. 
Afsari, Maásumeh. (2015). "Guidelines for reducing the stress and elevating the mental health in the job area." Website of Management essays.

Ahmadi, Abdollah. Iranian, Seyyed javad, and Parsanejad, Maásumeh. (2011).the relation between organizational creativity and job satisfaction of employees of Agricultural Jihad Organization of Fars Province." Quarterly periodical of Organizational industrial psychology.

Ahsan, N., Abdullah, Z., Yong Gun Fie, D., \&Alam, S. S. (2009). A Study of Job Stress on Job Satisfaction among University Staff in Malaysia: Empirical Study. European Journal of Social Sciences, 8 (1).www.eurojournals.com/ejss_8_1_11.pdf

Armstrong, Michael. (2001). "Approaches to the human resource management." Translated by Khodayar Abili and Movaffagi, Hasan. $1^{\text {st }}$ publication. Tehran. Farda Publication.

Azad marzabadi, Esfandyar, Tarkhourani, Hamid. (2007).Scrutinization of the relationship between job stress and job satisfaction of the employees." Journal of behavioral sciences.

Barahuyi, Shahbaz, Hashemi, Seyyed abulhasan. (2012). Scrutinization of the factors influencing job satisfaction." Website of Management essays.

Bavandpour, Abdollah. (2013). "Job stress and its role in the optimal performance of administrative employees. Website of management essays.

Davari SA. Health and its determinants. Tehran, contemporary works, 2007: 25.3.

Davis K, Newstrom J. Human Behavior In Work (Translated By Tusi MA). Markaze Amushe Modiriate Dolati Press; 1991

Dormin, C., Bölling, T., Wypior, H.J., Zehentmayr, F., Schulze, W., and s Geinitz, H. (2009). Job stress and job satisfaction of physicians, radiographers, nurses and physicists working in radiotherapy:

Fairborother, Kerry, and et al. 2003. Workplace dimensions, stress and job satisfaction. Journal of Managerial Psychology, 18(1).

Ghazizadeh, Mostafa, Amani, Jamshid. (2006). Scrutinization of the factors influencing the organizational retaining of employees: a case study. One of the grand production companies under the aegis of The Mostazafan Foundation of Islamic Revolution of Iran." 1st National symposium on Industrial Management.

Golparvar, Mohsen, Javadian, Zahra, Adibi, Zahra, Mosahebi, Mohammadreza, Ahmadi, Akram. (2013). the relation between job stress and job abandonment and functional performance with the mediator role of job satisfaction." Quarterly periodical of occupational health of Iran.

Hyde, Paula et al. 2005. Role redesign: new ways of working in the NHS. Personnel Review 34(6).

Kazemi, Babak. (2013). "Handbook of job safety and hygiene." Website of Management essays.

Mardani, Shadi et al. (2013). "Relationship between job satisfaction and the EHS performance of the employees in the casting industry." Quarterly periodical of occupational health of Iran.

Mehrabian, Fardin, Falaki, Seyyed hamid, Seyyed fazli, Seyyed mohammad. (2013). "Role of general health in job satisfaction. Journal of Health and Hygiene.

Mirsepasi, Naser. (1996). "Human resource Management and the strategic- attitudinal job relations. Tehran. Shervin Publication.

Moghannibashi, Elaheh, Mansurieh et al. (2013). "Security attitude in the rehabilitation clinics of Ahvaz." Journal of improving security and preventing the injuries.

Mohammadfam, Iradj et al. (2003). "An introduction to the security and hygiene in the electronics technology." Website of Management essays.

Nasiripour, Amir Ashcan, Nikoomaram, Hanieh, Behzadi, Mohammadhasan, Mardani, Nooshin. (2012). "Relation between organizational health culture and the occupational commitment of the employees." Quarterly periodical of occupational health of Iran.

Sehlen, S., Vordermark, D,Schäfer, C., Herschbach, P., Bayerl, A., Pigorsch, S., Rittweger, J.,

Taghdisi, Mohammadhoussein, et al. (2013). "Evaluation of security culture in one of the oil refineries." The scientific-research Quarterly periodical of teaching hygiene and elevating the health. No.3.

Vafayinejad, Maryam, Heidari gordji, Alimorad, Nadighara, Asghar. (2013). "Scrutinization of the factors influencing the retaining and survival of the administrative staff of the undersecretary of developing management and the resources of the University of Medicine and Hygiene and treatment services of Mazandaran. Website of Management journals.

Wahabich, Houssein. (2006). "Job security with an inclination towards safety and hygiene and its role in retaining the employees of an organization." Website of Management essays.

Warren, Richard C. 1996. The empty company: morality and job security. Personal Review 25(6) 41-53. 